\title{
LUTA PELA TERRA UM PROCESSO HISTÓRICO EM DISCUSSÃO, SOB A ÓTICA DA VIOLÊNCIA, EXCLUSÃO E DA CONCENTRAÇÃO FUNDIÁRIA.
}

João Mateus de Amorim ${ }^{1}$

(1 - Professor de Geografia - Escola Agrotécnica Federal de Uberlândia mateusamorim@terra.com.br)

\section{RESUMO}

Este artigo faz uma abordagem da questão fundiária do campo brasileiro. Essa abordagem também permitirá estabelecer possíveis discussões, com vistas, ao entendimento das ações humanas sobre o espaço rural. O viés de discussão deste trabalho é pautado na busca pela Terra e pela Reforma Agrária com o intuito de resgatar a dignidade dos expropriados do campo. Os privilégios e a Lei de Terras foram os principais instrumentos para a concentração de terras no país. E mais tarde, sem a resolução da estrutura fundiária, a modernização no campo veio para aumentar o tamanho das fazendas de "Plantation" voltadas para a exportação. O espaço agrário brasileiro esteve sempre nas mãos de uma elite agrária arcaica, concentradora e anti-social, enquanto o povo ficava sem espaço para a produção de alimentos e conseqüentemente sem condições para a subsistência familiar.

Palavra chave: Concentração de Terras, Reforma Agrária, Movimentos Sociais no Campo.

\section{ABSTRACT \\ FIGHT FOR THE LAND A HISTORICAL PROCESS IN QUARREL, UNDER THE OPTICS OF THE VIOLENCE, THE EXCLUSION AND THE AGRARIAN CONCENTRATION.}

This article makes a boarding of the agrarian question of the Brazilian field. This boarding also will allow to establish possible quarrels, with sights, to the agreement of the actions human beings on the agricultural space. The bias of quarrel of this work is pautado in the search for the Land and the Agrarian Reformation with intention to rescue the dignity of the expropriated ones of the field. The Land privileges and Law had been the main instruments for the land concentration in the country. E later, without the resolution of the 


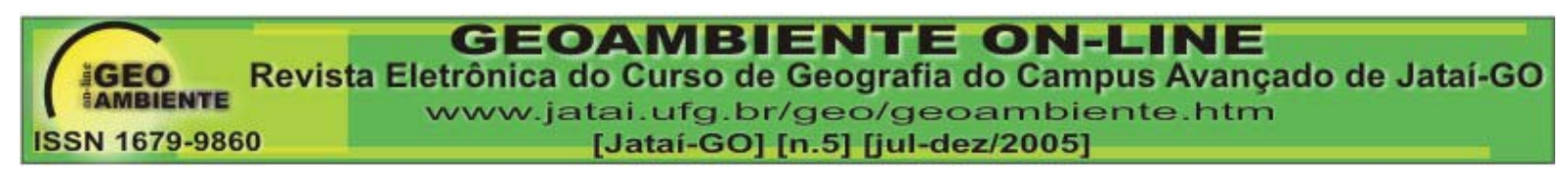

agrarian structure, the modernization in the field came to increase the size of the farms of "Plantation" directed toward the exportation. The Brazilian agrarian space was always in the hands of the archaic, concentrative and antisocial elite agrarian, while the people was without space for the food production for the familiar subsistence.

Keyword: Concentration of Lands, Reforms agrarian, Social Movements in the Field.

\section{Introdução}

O objetivo deste trabalho tem como base a busca de um referencial teórico que dê sustentação ao tema intitulado a luta pela terra, liberdade e à vida. A pesquisa foi realizada com base na referência bibliográfica apresentada no final do mesmo.

A justificativa deste artigo se confirma, principalmente, no levantamento histórico do processo de concentração fundiária, no qual a elite (classe dominante) do país, sempre foi dotada de privilégios e benefícios referindo-se aos aspectos econômico e político. Isso demonstra a situação perversa que se encontra a realidade do Brasil, tanto nos aspectos sociais, econômicos, políticos, culturais e ambientais. Sendo assim queremos mostrar alguns pontos acerca da luta pela terra em face da concentração fundiária. Essa concentração vai se estabelecer com mais intensidade a partir do processo de modernização do campo. Este processo expropriou a classe trabalhadora do/no campo e destruiu a natureza (o cerrado brasileiro foi quase extinto, fruto desse processo). A modernização via mecanização da agricultura (DELGADO, 1985; MÜLLER, 1989) estabeleceu uma dinâmica apoiada na concentração, na exclusão e na destruição dos ecossistemas naturais.

Neste contexto vamos traçar um levantamento da história relacionada à posse da terra no Brasil. Apontaremos as causas das desigualdades socioeconômicas de hoje, que na maioria das vezes são frutos de privilégios e sucessão hereditária ${ }^{2}$ em torno da terra. Estes fatos podem corroborar as desigualdades de hoje, tanto no campo como no meio urbano.

\footnotetext{
2 Dá-se através da partilha da terra entre os filhos. Isso faz com que esta família permaneça no curso da história com os privilégios da posse da terra, da renda e da política. Esse processo vai mudar um pouco a partir de 1930 com a urbanização e industrialização. Mas esse privilégio perdurará pela passagem dos bens da terra para os bens de produção da área urbana. Muitos proprietários de terras educaram os seus filhos para assumir os postos de trabalho da classe média urbana, como: engenharia, medicina, magistratura, professores, arquitetos e outros.
} 


\section{A concentração fundiária e os conflitos agrários.}

Do período colonial até a república velha predominaram-se a concentração de terras e os privilégios de uma elite latifundiária voltada para a propriedade rural. Este processo deu sustentação com a Lei de Terras, pois excluiu os ex-escravos da posse da terra. Estes instrumentos afirmaram ainda mais o poder destes coronéis ${ }^{3}$ do campo brasileiro.

Durante todo período desenvolvimentista, de 1930 até 1960, as políticas públicas voltadas para o campo foram baseadas em Programas de Colonização e até mesmo deixadas de lado, não causando nenhuma modificação na estrutura de posse da terra. No período subseqüente, da Ditadura Militar, fase de crédito fácil e barato e de políticas agrícolas de cunho modernizante, a legislação agrária foi benéfica apenas para os grandes proprietários, sendo os pequenos produtores rurais lembrados somente durante os conflitos pela posse da terra. Atingiu-se como resultado do agravamento da concentração fundiária e a instalação de uma profunda miséria no campo brasileiro, uma vez que foi a fase de consolidação do capitalismo no campo através dos CAI's (DELGADO 1985; MÜLLER, 1989).

A atual Constituição (1988) criou a possibilidade de "desapropriar por interesse social, para fins de reforma agrária, o imóvel rural que não esteja cumprindo sua função social”, definida por leis complementares. A reforma agrária torna-se incompatível com esse modelo arcaico, concentrador, elitista e anti-social. Então como fazer reforma agrária nessas condições apresentadas? A nossa estrutura fundiária privilegia uma elite latifundiária e excluem uma multidão de pessoas ao desemprego, à fome, à miséria e à perspectiva de viver com dignidade tanto no campo como na cidade. Restando a essa população marginalizada a busca pela terra de produção para sobreviver, enquanto que a outra classe utiliza a mesma terra para concentrar, produzir riquezas como reserva de valor ${ }^{4}$. Esses fatos produzem conflitos pela terra que somente se resolverá por uma reforma na estrutura agrária.

Desde então, a questão agrária vem se avolumando como um dos mais graves problemas nacionais, sofrendo seu maior golpe na Constituição de 1988, que aumentou o fosso entre os proprietários de terra e os sem-terra; e assumindo caráter emergencial nos anos 90 em decorrência do processo de globalização da economia, bem como da adoção dos

\footnotetext{
3 São os donos de grandes glebas de terras que detinham o poder econômico, político e social do espaço onde estavam inseridos, principalmente durante a república velha (1890 a 1930) perdurando até hoje no nordeste brasileiro.

4 Esse processo dá-se pela concentração de terras em locais improdutivos a espera de investimentos para a obtenção de lucros.
} 


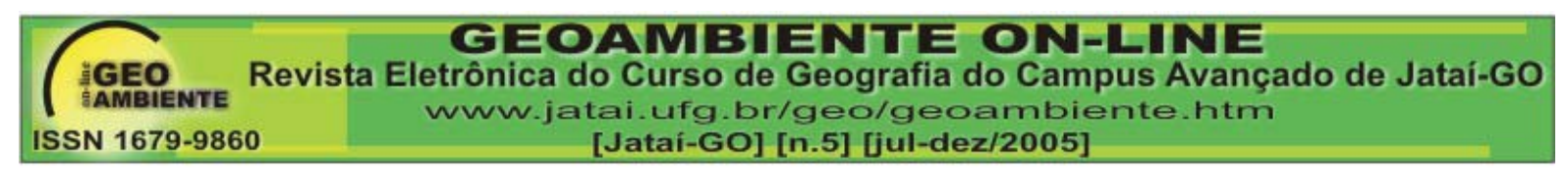

pressupostos neoliberais pelo Estado brasileiro, quando se passa a dar sustentação acumulação de capital de maneira diferente das décadas passadas, isto é, não mais atuando diretamente como financiador das suas atividades, mas deixando esse agir livremente de acordo com as leis de mercado (MARTINS, 1995).

Contudo, distintas concepções de reforma agrária, a complexidade do problema e os interesses díspares dos envolvidos tornam lentas a desapropriação e a demarcação de terras. A reforma agrária no Brasil deve ser debatida como princípio de justiça social e instrumento de modernização econômica e de consolidação democrática, muito além de uma questão ideológica. Os conflitos que se sucedem no campo são frutos da modernização excludente e concentradora no campo.

Esses conflitos são conseqüências de um problema enfrentado no início da colonização até hoje pela sociedade: os absurdos níveis de concentração da propriedade da terra vigentes no Brasil e às distorções no acesso ao trabalho com a terra. A concentração da terra na mão de poucos proprietários determina um círculo vicioso que acaba impedindo o desenvolvimento de amplas parcelas da população, reproduzindo uma cadeia seqüencial de miséria econômica, social, política e cultural que se abate sobre o campo e a cidade. È por isso que a questão agrária não envolve apenas aspectos agronômicos, econômicos, sociais e fundiários, ou seja, a concentração da estrutura agrária na mão de poucos.

No processo político de cunho neoliberal a questão da terra deixa de ser social e passa a ser política. Nesse sentido a Reforma Agrária não seria uma política de desenvolvimento, mas apenas compensatória, destinada a ajudar famílias miseráveis e a controlar determinados conflitos. O Estado seria o principal articulador de toda a política e de suas prioridades. Essa reforma não mexe na estrutura agrária, pois não muda os instrumentos que dão sustentação à propriedade que são: polícia, Estado, justiça, religião e as leis que privilegiam uma elite latifundiária, baseada na herança escravocrata e na exploração humana.

Esse processo acirra com mais intensidade a partir da globalização ligada ao movimento mais amplo do capital mundial, agravando a situação dos pequenos produtores e trabalhadores do campo. Uma vez que, apenas a parte mais moderna da agricultura nacional e os CAI's conseguem se integrar ao mercado mundial, deixando, à margem, o trabalhador rural brasileiro. Como reflexo da "saída do Estado da economia", os conflitos e a violência no campo aumentaram; como aumentou também, a concentração das terras e as péssimas condições de vida do homem do campo (DELGADO 1985; MÜLLER, 1989).

E, neste momento atual, com a entrada do governo Lula na presidência do Brasil em 2003, ainda continua bastante tenso a questão da luta pela terra. Os excluídos da terra estão esperando uma reforma agrária de verdade, que atenda a massa de excluídos como um todo e 


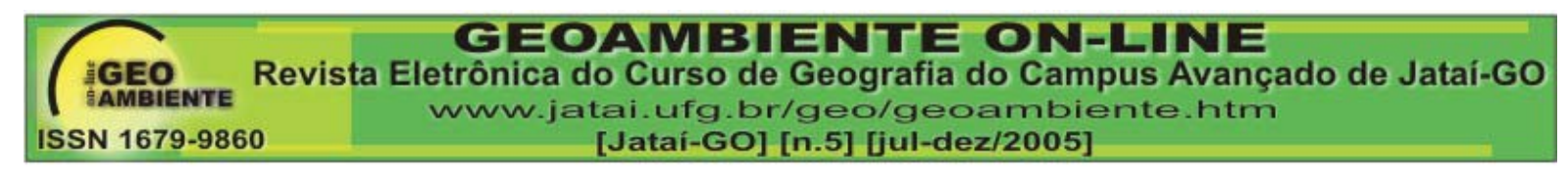

de forma a privilegiar aos anseios desta classe marginalizada desde o início da colonização do Brasil.

\section{O embate entre UDR e MST.}

A UDR além de ter como prática, o enfrentamento e a violência contra os trabalhadores sem-terra, representam à arregimentação do patronato rural, ou seja, o braço organizativo dos latifundiários e a representação da proteção e manutenção da estrutura fundiária no país.

Com a crescente mobilização dos trabalhadores sem-terra e a luta pela terra, os grandes proprietários, organizados pela UDR deflagraram um intenso processo de violência contra os trabalhadores sem-terra na tentativa de anular a reforma agrária e destruir o movimento de luta pela terra. Diante do exposto, acreditamos que as legitimidades da representação das elites agrárias têm, nos meios de comunicação, um poderoso instrumento que assegura a defesa desse padrão de propriedade latifundista, portanto de um ordenamento territorial específico, a partir do qual exerce a dominação de classe e desqualifica o movimento dos trabalhadores sem-terra e a luta pela terra como um todo.

A ocupação de terras pelo MST, posseiros e trabalhadores rurais na busca pela terra para produzir o alimento de sua subsistência constitui-se numa ação política e social muito importante. Esta atitude política dos movimentos sociais rurais na luta pela terra, ataca de cheio as bases do poder da classe latifundiária (FERNANDES, 1999).

Neste sentido, como estamos nos referindo a realidades distintas, ou seja, a ação do poder político local - elites agrárias - e a ação do MST, essa disputa representa não só formas de mobilização, como também estratégias de organização e de ação sócio-espacial tanto da burguesia local quanto dos trabalhadores sem-terra em geral.

Frente a essa disputa, ou a forma como essa face da luta de classe se apresenta, têm-se os assentamentos rurais que são produtos dessa correlação de forças e dos embates que foram estabelecidos ao longo do processo de luta pela terra, e que resultaram em mudanças que são expressas territorialmente. A análise dessas mudanças ocorridas no território nos permitirá compreender a dimensão e a magnitude da luta pela terra noticiada pelos meios de comunicação. (FERNANDES, 1999). 


\section{MST e a luta pela terra.}

A luta pela terra, pela reforma agrária e por um novo tipo de sociedade, mais justa, solidária e democrática, sendo que, com estes objetivos surgiu o movimento dos Trabalhadores Rurais sem Terra na década de 70. O MST nasceu em um momento de resistência contra a política de desenvolvimento agropecuário implantada durante o regime militar. Mais do que a luta pela terra, o MST deseja transformar as relações de poder no Brasil.

As políticas que eram desenvolvidas pelo governo para a solução do problema sempre foram aplicadas de forma ineficiente, lesando constantemente o trabalhador rural. Estes trabalhadores, cansados de promessas, resolvem se organizar. Os primeiros movimentos que surgem não têm muita representatividade no cenário nacional, o que dificulta o seu andamento e sua luta. Já em 1978, com o surgimento do MST, que desde o seu início tem a representação de dezesseis Estados e hoje faz com que sua articulação esteja presente em todos os Estados. O surgimento deste movimento faz o debate sobre a Reforma Agrária para um cenário maior, saindo do campo e chegando até à população urbana, esta que também vem sofrendo muito com a atual conjuntura, pois o desemprego e a fome estão atingindo uma grande camada da população e estes fazem com que à vontade de mudança torne-se unânime na construção de uma nova vida (FERNANDES, 1999).

O Movimento dos Trabalhadores Rurais Sem-Terra (MST) nasceu de enfrentamento e resistência contra a política de desenvolvimento agropecuário, instaurada durante o regime militar. Esse processo é entendido no seu caráter mais geral, na luta contra a expropriação e contra a exploração do desenvolvimento do capitalismo [...] a primeira fase desse momento histórico da luta pela terra e da formação do MST, compreendido entre 1978 e 1985 [...] período da luta pela democracia, de transição política e de rupturas, a classe trabalhadora retoma suas perspectivas conquistando novos espaços no campo e na cidade [...] o MST começou a ser gerado no espaço social conquistado pelas diversas experiências das lutas populares: estratégia político-cultural concebido no universo destes sujeitos (FERNADES, 1999, p. 65-66).

O MST em seus vinte e sete anos de existência, considerando a origem a partir de 1978, com base em Fernandes, 1999, este movimento, através da sua própria experiência de reivindicação, elaborou uma proposta de luta pela Reforma Agrária. Segundo a sua concepção, a reforma agrária é importante não só para o desenvolvimento econômico, mas 


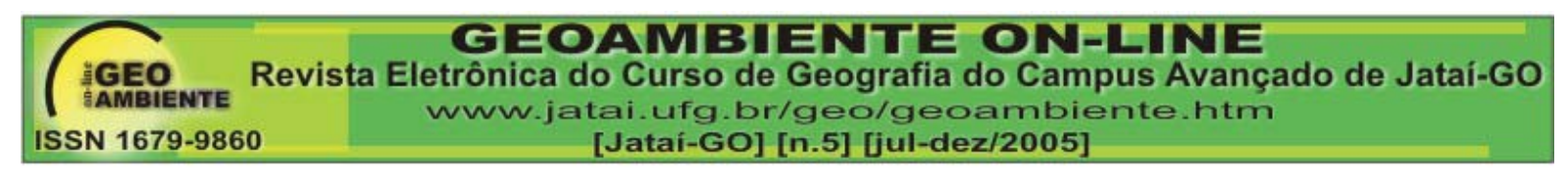

também para uma transformação política de como a questão da terra foi tratada até então. Sua práxis concentra-se na ocupação da terra, procurando conquistar os meios necessários para a realização de assentamentos e de meios para que as famílias despossuídas, ou seja, totalmente precarizadas passem produzir para garantir no mínimo a subsistência familiar. Com os assentamentos, a melhoria das condições sociais das famílias é uma realidade. Além disso, a partir de sua produção já se observa em várias localidades e Estados o Desenvolvimento da economia local. Esta luta tem mudado um pouco a estrutura fundiária brasileira e hoje se tornou uma das principais bandeiras da classe trabalhadora. Desta forma, hoje é impossível pensarmos em igualdade, crescimento econômico e democracia se deixarmos de lado a questão da reforma agrária (FERNANDES, 1999).

[...] no campo, em diversos estados, aconteceram lutas localizadas que deram origem ao MST. As lutas que marcaram o princípio da história do MST foram às ocupações das glebas Macali e Brilhante, no município de Ronda Alta-RS, em 1979; a ocupação da fazenda Burro Branco, no município de Campo de Erê-SC [...] no Paraná [...] e a construção da barragem de Itaipu [...] em São Paulo a luta dos posseiros da fazenda Primavera nos municípios de Andradina, Castilho e Nova Independência; no Mato Grosso do Sul, nos municípios de Naviraí e Glória de dourados, milhares de trabalhadores rurais arrendatários desenvolviam uma tensa luta pela resistência. Outras lutas também aconteciam nos Estados da Bahia, Rio de Janeiro e Goiás (sic) (MST, 1986; MEDEIROS, 1989; STÉDILE \& GORGEN, 1993 apud FERNANDES, 1999, p. 66-67).

Com a abertura política e a redemocratização, os trabalhadores rurais reorganizaram-se e intensificaram sua ação ganhando o apoio da Igreja. Criado a partir de 1978, o MST começou reivindicando terra e combatendo os latifúndios improdutivos; depois, passou a discutir a distribuição do dinheiro público, a invadir qualquer propriedade e a propor a tomada do poder (FERNANDES, 1999).

Mas apesar dos avanços fica claro o arrefecimento da legitimidade na posse da terra tanto do posseiro quanto do MST, pois ambos não têm condições econômicas para brigar na justiça pelo domínio da terra para a produção. A institucionalização do Estado para assegurar os esteios da dominação, ainda que seja, pela informalidade desta com a figura do Grileiro, o qual usa de meios ilegais para escriturar parcelas de terra, na maioria das vezes com a ajuda da justiça, da polícia e do Estado. O enfrentamento político dessa situação dá-se com as prisões de Líderes Sem-Terra e o enquadramento desse fato como "bandos e formação de quadrilhas" (FERNANDES, 1999, p. 209) pelo judiciário. A “Judiciarização dos conflitos fundiários" (FERNANDES, 1999, p. 210) tem como base aspectos políticos, com apoio da 


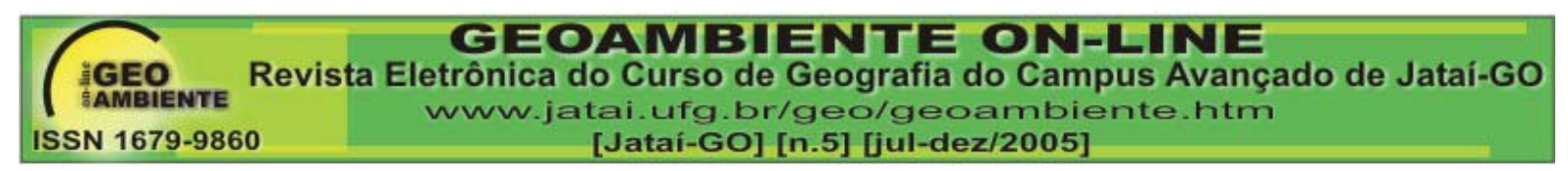

justiça para conservar uma elite agrária no poder econômico e político neste país. O grileiro usando do apoio da justiça expropria os posseiros e os integrantes do MST para a luta em busca de terra e de sobrevivência no campo.

\section{Conclusão}

Tendo seus alicerces firmados há quinhentos anos, hoje, no início do século XXI, o Brasil ainda não conseguiu solucionar sua questão agrária. Famílias ainda estão sem terra para plantar ou sem assistência médica, crianças ainda morrem desnutridas e outras, em idade escolar, não estão aprendendo a ler e escrever.

Para resolver essa situação não basta só os Programas de Assentamento, e sim de mudanças na estrutura fundiária. Os Assentamentos, no Brasil, funcionam como mera política assistencialista; onde se dá terra, mas não se dão as condições de permanecer nela, e onde são lançados programas e mais programas que não são postos em prática. Essa é a questão agrária brasileira, um problema que transcende o campo e invade as cidades, que assume contornos econômicos, sociais e políticos, que pedem solução.

Após termos visto e analisado a forma como a questão da terra foi tratada no Brasil desde a sua descoberta até os dias de hoje, não fica difícil compreender o motivo pelo qual este quadro se apresenta de forma tão problemática e de difícil debate, pois há de um lado o povo que necessita da terra para sua subsistência e de outro os proprietários de grandes latifúndios que, muitas vezes, têm a propriedade da terra apenas como uma forma de investimento, ou seja, a terra de negócio ${ }^{5}$. O início da colonização, a forma como foi distribuída a terra, colaboraram imensamente para a formação dos latifúndios, os quais foram efetivados com uma política de legitimação de propriedade que beneficiou quem tinha condições financeiras de fazê-la.

\section{Referências bibliográficas}

DELGADO, Costa Guilherme. Capital Financeiro e Agricultura no Brasil: 1965-1985. São Paulo. Ícone e UNICAMP. 1985. Cap 1. 19-49p.

FERNANDES, Bernardo Mançano. MST: Formação e Territorialização. $2^{\mathrm{a}}$ ed. São Paulo: Hucitec, 1999. 285p. 


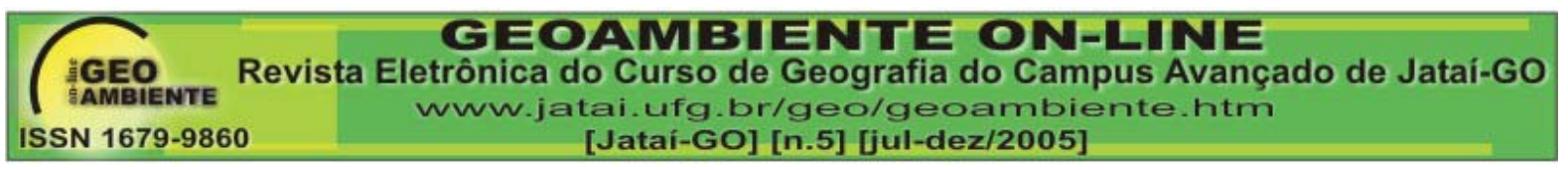

MARTINS, José de Souza. O cativeiro da terra. São Paulo: Hucitec, 1986. 157p.

- Os camponeses e a política no Brasil. $5^{\mathrm{a}}$ ed. Petrópolis. Ed.

Vozes. 1995. 232p.

. Reforma Agrária. O impossível diálogo. São Paulo: Recorde.

2000. 176p.

MÜLLER, Geraldo. Complexo Agroindustrial e Modernização Agrária. São Paulo, Educ. e HUCITEC, 1989. 149p.

OLIVEIRA, Ariovaldo Umbelino de. A Geografia das Lutas no Campo. São Paulo: Contexto, 1996. 101p.

SILVA, J. G. da. O que é questão agrária. $16^{\mathrm{a}}$ ed. Coleção Primeiros Passos 18. São Paulo: Brasiliense, 1996. 110p. 